\title{
TRAIL-induces apoptosis but not necroptosis in colorectal and pancreatic cancer cells preferentially via the TRAIL-R2/DR5 receptor
}

Zuzana Nahacka ${ }^{1,2}$, Jan Svadlenka ${ }^{1, ~ *}$, Martin Peterka ${ }^{1, \text { \#, Marie Ksandrova }}{ }^{1,}$, Simona Benesova, Jiri Neuzil ${ }^{2,5}$ and Ladislav Andera ${ }^{1,2}$

\section{Affiliations}

${ }^{1}$ Institute of Molecular Genetics, Czech Academy of Sciences, Prague, Czech Republic;

${ }^{2}$ Institute of Biotechnology, Czech Academy of Sciences, Vestec, Czech Republic; ${ }^{5}$ School of Medical Science, Griffith University, Southport, Qld, Australia;

* present address: Biorad CZ, Prague, Czech Republic

\# present address: Institute of Biochemistry, ETH Zürich, Zürich, Switzerland

Correspondence:

Ladislav Andera, PhD, Institute of Biotechnology, Czech Academy of Sciences, Prumyslova 595, 25250 Vestec, Czech Republic; email: andera@ibt.cas.cz

Key words: TRAIL, apoptosis, necroptosis, receptor-specific signaling, cancer. 


\section{Abstract}

Tumor necrosis factor-related apoptosis-inducing ligand (TRAIL) is a cytokine that can trigger apoptosis in many types of human cancer cells via engagement of its two pro-apoptotic receptors TRAIL-R1 (DR4) and TRAIL-R2 (DR5). TRAIL can also activate several other signaling pathways such as activation of stress kinases, canonical NF- $\kappa \mathrm{B}$ signaling and necroptosis. Though both receptors are ubiquitously expressed, their relative participation in TRAIL-induced signaling is still largely unknown. To analyze TRAIL receptor-specific signaling, we prepared Strep-tagged, trimerized variants of recombinant human TRAIL with high affinity for either DR4 or DR5 receptor. Using these receptor-specific ligands, we examined the contribution of individual pro-apoptotic receptors to TRAIL-induced signaling pathways. We found that in TRAIL-resistant colorectal HT-29 cells but not in pancreatic PANC-1 cancer cells, DISC formation and initial caspase- 8 processing proceeds comparably via both DR4- and DR5-activated signaling. TRAIL-induced apoptosis, enhanced by the inhibitor of the Bcl-2 family ABT-737, or by the translation inhibitor homoharringtonine, proceeded in both cell lines predominantly via the DR5 receptor. ShRNA-mediated downregulation of DR4 or DR5 receptors in HT-29 cells also pointed to a stronger contribution of DR5 in TRAIL-induced apoptosis. In contrast to apoptosis, necroptotic signaling was activated similarly by both DR4- or DR5-specific ligands. Activation of auxiliary signaling pathways involving NF- $\mathrm{NB}$ or stress kinases proceeded under apoptotic conditions mainly in a DR5-dependent manner, while these signaling pathways were during necroptosis similarly activated by either of these ligands during necroptosis. Our study provides the first systematic insight into DR4-/DR5-specific signaling in colorectal and pancreatic cancer cells.

\section{Introduction}

TRAIL ligand (Apo-2L, TNFSF10), a member of the TNF ligand superfamily is expressed mainly by cells of the immune system. It can induce apoptosis in many types of human cancer cells [1-4]. However, depending on the tumor type, and the concurrent signaling, TRAILtriggered cellular responses can also be pro-tumorigenic, enhancing cell survival and proliferation via non-canonical signaling [5-7]. Human TRAIL ligand binds two pro-apoptotic receptors; DR4 (TRAIL-R1) and DR5 (TRAIL-R2) and three decoy receptors DcR1 (TRAILR3), DcR2 (TRAIL-R4) and osteoprotegerin, which not only compete with DR4/5 for the ligand binding, but are also capable of transducing non-apoptotic pro-survival signaling as 
shown for the truncated DcR2. Binding of TRAIL to DR4 or DR5 triggers formation of the death-inducing signaling complex (DISC), containing the core adaptor protein FADD, procaspase- 8 and the anti-apoptotic protein c-FLIP, which represents a platform for proximitybased, self-processing and activation of the initiator caspase-8, essential for TRAIL- or FasLinduced apoptotic signaling. In addition to pro-apoptotic signaling, TRAIL is capable of inducing a process called necroptosis in cells with inhibited caspases and free RIP1 kinase. Necroptosis proceeds by triggering the formation of the RIP1-activating intracellular complex, necrosome, containing FADD, c-FLIP, caspase-8, and RIP1 and RIP3 kinases [8]. Moreover, TRAIL can induce pro-survival NF- $\kappa \mathrm{B}$ and MAP/stress kinase signaling similarly as FasL, involving the cytosolic complex consisting of FADD, TRADD, TRAF2, caspase-8, RIP1, NEMO and other proteins, (recently reviewed in [9]).

In 1999, Walczak and colleagues showed that recombinant human and murine TRAIL ligands can selectively and effectively trigger apoptosis of transformed cells also in vivo, and unlike other death-inducing ligands of the TNF family, systemic application of TRAIL did not manifest severe side effects, e.g. hepatotoxicity. This boosted interest in the TRAIL proapoptotic signaling and led to the development of a number of recombinant ligands and agonistic anti-DR4/-5 antibodies. However, clinical trials using recombinant TRAIL Dulanermin (Genentech) and several humanized agonistic antibodies were rather disappointing, having shown only a limited anti-tumor effect [10]. The mechanism underlying the resistance of cancer cells to TRAIL-induced death could be a result of a variety of factors acting at different levels of the TRAIL signaling pathway, such as suppressed cell surface expression of its pro-apoptotic receptors, impaired activation or activity of caspase- 8 due to mutations, epigenetic silencing or ubiquitination, or also overexpression of a number of antiapoptotic proteins such as the inhibitor of caspase- 8 c-FLIP, or inhibitors of apoptosis (IAP) family members and anti-apoptotic proteins from the Bcl-2 family [11]. Moreover, recent publications document that tumor cells can, under suppressed apoptosis, hijack TRAILinduced signaling for proliferation and secretion of pro-tumorigenic soluble factors [7, 12-14].

The expression of two death-inducing TRAIL receptors in human and monkey cells compared to other mammals, which have only one pro-apoptotic TRAIL receptor and only 46-48\% sequence identity of DR4 with DR5, suggests a structural, functional and regulatory difference between both receptors. Indeed, several studies with selective recombinant TRAIL ligands or DR4-/DR5-specific agonistic antibodies, have indicated possible selectivity of DR4 vs. DR5 apoptotic signaling in tumor cells of various origin. For example, pancreatic carcinoma, chronic lymphocytic leukemia or mantle cell lymphoma prefer DR4 for the 
induction of apoptosis; other types, such as colorectal or other epithelial cancer cells appear to prefer DR5 as an apoptosis inducer [15-20]. TRAIL receptor-specific ligands or agonistic antibodies have also increased affinity for their cognate receptor but very low affinity for decoy receptors, and thus might induce more robust and faster induction of cell death in tumor cells [21]. In our study, we aimed to analyze in detail the canonical and non-canonical signaling from our modified and enhanced TRAIL receptor-specific ligands in a model of colorectal and pancreatic cancer cells. We show that the DR5 receptor plays a major role in the induction of apoptosis as well as of non-canonical signaling in colorectal HT-29 cells, but not in the induction of TRAIL-triggered necroptosis. We also document preference for DR5 in apoptosis induction in the pancreatic cancer PANC-1 cells.

\section{Materials and methods}

\section{Twin-Strep-tag TRAIL ligand variants and reagents}

Twin-strep-tag in-frame with bacteriophage trimerization (TRI) motif [22] was synthetized (GeneScript) and sub-cloned upstream of the human TRAIL cDNA (extracellular part, amino acids 95-271) into pBKSII, resulting in pBKSII- TST-TRI-TRAIL-wt. TRAIL receptorspecific mutants DR4.02 (G131R/R149I/S159R/N199R/K201H/S215D, 4C7 mutant; [21]), DR5.01 (E195R/D269H; [19]) and DR5.02 (Y189N/R191K/E195R/H264R/I266L/D269H; [23]) were synthetized (Genscript) and sub-cloned into the pBSKII-TST-TRI plasmid. TSTtagged TRAIL ligands were inducibly expressed in the BL21-AI bacterial strain (Thermo Fisher), and proteins were purified using Gravity flow Strep-Tactin Sepharose column (IBA), according to the manufacturer's protocol.

Apoptosis was induced using human recombinant TRAIL ligand variants (see above) in combination with homoharringtonine (Sigma-Aldrich) or ABT-737 (Selleck Chemicals). TRAIL-mediated necroptosis was induced in cancer cells pre-treated with the IAP inhibitor birinapant (Selleck Chemicals) and pan-caspase inhibitor Z-VAD-FMK (Enzo LS). Necroptosis inhibitors necrostatin-1 and necrosulfonamide were obtained from Selleck Chemicals and from Tocris, respectively.

\section{Cell lines and culture conditions}

Human colorectal adenocarcinoma cell line HT-29, human pancreatic adenocarcinoma cell line PANC-1 and human kidney epithelial cells HEK293T were obtained from the ATCC. B- 
cell lymphoma cell line Ramos and the acute T-cell leukemia cell line Jurkat were kindly provided by V. Horejsi (Institute of Molecular Genetics, Czech Academy of Sciences) and were originally also obtained from ATCC.

The cells were cultured in DMEM (HEK 293T, HT-29, PANC-1) or in RPMI (Jurkat, Ramos) supplemented with v/v 10\% FCS (Life Technologies), L-glutamine and antibiotics. In the case of PANC-1, non-essential amino acids (Life Technologies) were added to the medium. Cells were kept in a humidified incubator at $20 \%$ oxygen, $5 \% \mathrm{CO}_{2}$ and $37^{\circ} \mathrm{C}$. All unspecified media and cell culture additives were purchased from Sigma.

\section{Preparation of recombinant lentiviruses and transduction of cells}

Recombinant lentiviruses were obtained from calcium-phosphate transfected HEK 293T cells using packaging plasmids psPAX2 (Addgene, 12260) and pMD2.G (Addgene, 12259) together with either pLKO empty, pLKO non-targeting shRNA or pLKO shRNA against DR4 and DR5 receptors (shDR4_\#1 TRCN0000005934,shDR4_\#2 TRCN0000005935, shDR5_\#1 TRCN0000005929, shDR5_\#4 TRCN0000005932, shDR5_\#5 TRCN0000005933). The medium containing lentiviral particles was harvested 36 to $48 \mathrm{~h}$ post-transfection, and the viral particules were precipitated using PEG-it (System Biosciences). Target cells were transduced with viruses at multiplicity of infection MOI 5-10 and selected for puromycine resistance $(2 \mu \mathrm{g} / \mathrm{ml}$, Invivogen $)$.

\section{Western blotting}

The cells were lysed in the standard $2 \times$ Laemmli buffer $(50 \mathrm{mM}$ Tris- $\mathrm{HCl} \mathrm{pH} 6,8 ; 20 \%$ glycerol; $4 \%$ SDS; $0.02 \%$ bromophenol blue, $200 \mathrm{mM} \mathrm{DTT)}$. The samples were subjected to SDS-PAGE, proteins were transferred onto a nitrocellulose membrane (Hybond ECL; Amersham), and proteins visualized using individual primary antibodies (if not stated otherwise, primary antibodies were obtained from Cell Signaling): caspase-8 1C12 (9746);

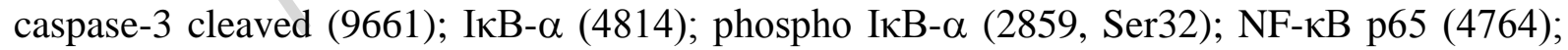
phospho NF-kB (3033, Ser536); phospho SAPK/JNK (9255S, Thr183/Tyr185); p38/MAPK (9212); phospho p38/MAPK (9211S, Thr180/Tyr182); phospho MLKL (14516, Thr357/Ser358); PARP (9532); caspase-3 (804-305-C100 Enzo); DR4 (8414, Abcam); MLKL (184718, Abcam); DR5 (D3938 Sigma-Aldrich); FADD (610400, BD); RIP1 (610458, BD); SAPK/JNK (sc-571, Santa Cruz); actin (1615, Santa Cruz); RIP3 (7604, $\mathrm{MAB}$ ), in combination with horseradish peroxidase-conjugated secondary antibodies (Jackson 
ImmunoResearch). The protein-antibody complexes were visualized by Western Bright ECL (Advansta) or SuperSignal West Femto Maximum Sensitivity (Thermo Scientific).

\section{Death inducing signaling complex (DISC) precipitation}

Cells grown to approximately $80 \%$ confluence were rapidly cooled and then incubated on ice for $20 \mathrm{~min}$ (to prevent internalization of the receptors). Twin-Strep-tag labeled TRAIL ligand variants (TST-TRI-TRAIL) were added to the concentration of $1 \mu \mathrm{g} / \mathrm{ml}$ for $15 \mathrm{~min}$, then the cold medium containing TRAIL was replaced with the $37^{\circ} \mathrm{C}$ medium without TRAIL, and the cells were incubated at $37^{\circ} \mathrm{C}$. At selected time points, the cells were washed with cold PBS, the cell pellets were lysed in ice-cold lysis buffer ( $1 \%$ NP-40, $20 \mathrm{mM}$ Tris-Cl pH 7.5, 150 $\mathrm{mM} \mathrm{NaCl}, 10 \mathrm{mM}$ EDTA, $10 \%$ glycerol) and supplemented with inhibitors of proteases (Complete, Roche) and phosphatases $\left(10 \mathrm{mM} \mathrm{NaF}\right.$ and $\left.1 \mathrm{mM} \mathrm{Na} \mathrm{VO}_{4}\right)$. Lysates were adjusted to the same protein concentration and the same amount of protein $(2 \mathrm{mg})$ was incubated with Streptactin beads (IBA) overnight at $4^{\circ} \mathrm{C}$ and then washed 3-4 times with 1 volume of icecold lysis buffer; the bound proteins were directly eluted with $2 \times$ Laemmli sample buffer $\left(95^{\circ} \mathrm{C}, 5 \mathrm{~min}\right)$ and analyzed by western blotting.

\section{Flow cytometry analysis}

For all flow cytometry assays, the cells were seeded in 12 or 24 well plates and harvested at $80 \%$ confluency. For annexin V-FITC assays, cells were harvested by trypsinization, washed with ice-cold PBS, then re-suspended in the annexin-binding buffer, and incubated on ice with annexin V-FITC (Apronex) at the final concentration of $2 \mu \mathrm{g} / \mathrm{ml}$ for $20 \mathrm{~min}$. After adding Hoechst 33258 to the final concentration of $0.5 \mu \mathrm{g} / \mathrm{ml}$, the samples were analyzed by using the LSRII flow cytomerer (Beckton Dickenson).

For the analysis of death receptor expression, cells were harvested by mild trypsinization, then washed with ice-cold PBS, and non-specific interactions were blocked with PBS containing $0.2 \%$ gelatine and $0.1 \%$ sodium azide (PBS-GA). The samples were incubated on ice with the primary antibodies against DR4 (10-403, EXBIO) and DR5 (11461, EXBIO) receptors at the final concentration of $10 \mu \mathrm{g} / \mathrm{ml}$ for $30 \mathrm{~min}$. After incubation, cells were washed twice with ice-cold PBS-GA and incubated with the secondary goat antimouse IgG1 conjugated with phycoerythrin (final concentration $4 \mu \mathrm{g} / \mathrm{ml}$; Southern Biotech) 
on ice for $30 \mathrm{~min}$. Cells were then washed twice with cold PBS-GA, resuspended in PBS-GA with Hoechst $33258(0.5 \mu \mathrm{g} / \mathrm{ml})$ and analyzed by flow cytometry (LSRII).

For quantification of cell death, cells were harvested with accutase, washed with HBSS with 5uM EDTA and resuspended in HBSS/EDTA. Propidium iodide was added to the final concentration of $2 \mu \mathrm{g} / \mathrm{ml}$, and cells were analyzed by flow cytometry (LSRII).

\section{Statistical analysis}

Statistical analysis was carried out using the GraphPad Prism 6 software. Experiments were performed in at least three biological replicates, data are presented as mean values \pm SEM, and statistical significance was evaluated using ANOVA with differences at $p \leq 0.05$ considered significant.

\section{Results}

\section{DR5 receptor-specific ligands are superior to DR4 ligands in triggering apoptotic} signaling in cancer cells

In this communication, we aimed to address and compare in detail apoptotic, necrotic and cell death-independent signaling triggered by DR4- or DR5-specific TRAIL ligands in human cancer cells. To achieve this goal, we prepared a set of modified TRAIL receptor-specific ligands containing the extracellular part (amino acids 95-281) of either wild-type (referred to as TST-TRAIL WT) or DR4- and DR5-selective ligand, T4 phage trimerization/stabilization (TRI) motif and the N-terminal TwinStrep tag (TST) (See Fig. S1A and the Methods part). The purified ligands were found to be highly specific and effective in inducing DR4- or DR5mediated apoptosis in both the predominantly DR4-signaling Ramos Burkitt lymphoma cells and the DR5-expressing Jurkat T cell leukemia cells (Fig. S1B-D).

Colorectal and pancreatic tumors belong to the most studied cancers in the context of TRAIL ligand-induced cell death. We have thus selected colorectal (HT-29) and pancreatic (PANC-1) cancer cell lines for our experiments. The two cell lines express both TRAIL receptors (Fig. 1F, G), with similar cell surface expression of DR4 and lower DR5 expression by PANC-1 cells. Though HT-29 cells feature low total DR4 expression (Fig. 1G), they show a similar DR4 cell surface expression as found in pancreatic PANC-1 cells (Fig. 1F). Both cell lines are also relatively resistant to apoptosis induced by TRAIL alone (HT-29 cells, Fig. 1D, left part; PANC-1, Fig. S2C). Therefore, we included the enhancers of TRAIL-induced apoptosis homoharringtonine (HHT; [24]) and the BH3 analogue ABT-737 [25] for efficient induction of apoptotic signaling. Apoptotic signaling is dependent on efficient activation of 
caspases, which in the case of TRAIL receptors starts with activation of the initiator caspase- 8 within the ligand-receptor-containing activation complex (recently reviewed in [9]). We therefore first examined the time scale of the activation of apical caspase-8, activation of its downstream effector caspase-3, and cleavage of one of its major targets, poly-ADP ribose polymerase (PARP). For enhancement of TRAIL-induced apoptosis, we pre-incubated HT-29 cells (Fig. 1A, B) or PANC-1 (cells Fig. S2A, B) cells with $100 \mathrm{nM}$ HHT for $1 \mathrm{~h}$ and then incubated them with $100 \mathrm{ng} / \mathrm{ml}$ TST-TRAIL variants for $30 \mathrm{~min}$ to $3 \mathrm{~h}$ (HT-29 cells) or 30 min to $5 \mathrm{~h}$ (PANC-1). In both cell lines we repeatedly observed not only more efficient, but also faster activation of both caspases downstream of DR5-specific ligands. Interestingly, compared to DR5.1, the ligand DR5.2 ligand was much more efficient in inducing the processing of caspases. When using ligands specific for the DR5 receptor, the cleavage of not only PARP (Fig. 1A, B, Fig. S2A, B) but also of the Bid protein, in particular in HT-29 cells with downregulated expression of Mcl-1 (Fig. S3B), was considerably more efficient when compared to the DR4.2 ligand.

Having documented that pro-apoptotic signaling triggered by DR5-specific ligands was more efficient in activation of caspases than engaging DR4 or in response to wtTRAIL, we next examined whether the enhanced processing of caspases is also reflected in more pronounced induction of apoptosis in target cells. Indeed, we found that the induction of apoptosis in both HT-29 and PANC-1 cells pre-treated with the enhancers HHT or ABT-737 was more robust in HT-29 (Fig. 1C, D) and PANC-1 cells (Fig. 1E) treated with DR5-specific ligands (especially in the case of the DR5.2 ligand). Similarly, using HT-29 cells with downregulated expression of the anti-apoptotic protein Mcl-1 (Fig. S.3A), DR5-selective ligands were more efficient in both induction of processing and activation of caspases (Fig. S3B) and in induction of apoptosis (Fig. S3C).

\section{TRAIL receptor-specific variants do not differ in the formation of death-inducing signaling complex in HT-29 cells}

Knowing that DR5-specific ligands are more effective in the induction of caspase processing and induction of apoptosis, and in order to uncover the underlying reasons, we next attempted to dissect the first and essential step in TRAIL receptor signaling, formation and composition of the death-inducing signaling complex (DISC). HT-29 (Fig. 2A) and PANC-1 cells (Fig. 2B) were treated with $1 \mu \mathrm{g} / \mathrm{ml}$ of wt, 4.2, 5.1 and 5.2 TST-TRAIL variants. Affinity purification of DISC components via Strep-tagged TRAIL ligands in HT-29 cells did not show any major differences in either DISC composition or in the kinetics of the formation of 
the DISC complex (Fig. 2A). However, we noticed that wtTRAIL as well as the DR4-specific ligand attracted FADD in contrast to DR5-selective ligands even during the pre-incubation on ice in both HT-29 and PANC-1 cells (Fig. 2A,B). In contrast to HT-29 cells, we noticed more effective processing of caspase-8 in DISC complexes of PANC-1 cells triggered by DR5selective ligands (notably DR5.2) (Fig. 2B), which was also reflected in stronger appearance of the processed p43/41 caspase-8 bands in the DR5.2 cell lysates. Interestingly, though DR5selective ligands triggered comparable or for DR5.1 even less effective DISC formation in HT-29 cells, caspase- 8 processing in the cell lysates appears to be more effective.

\section{DR5 but not DR4 downregulation results in lower susceptibility of colorectal cancer cells to TRAIL}

In order to further decipher and confirm the major role of the DR5 receptor in TRAILtriggered apoptotic signaling, we applied DR4- or DR5-specific lentiviral shRNAs constructs to downregulate their expression in HT-29 cells. Using two different DR4- and two different DR5-directed lentiviral shRNAs, plus the non-targeting shRNA (NT) and empty pLKO1 (EV) controls, we have documented that downregulation of either receptor expression (Fig. 3A, B) resulted in the suppression of DR4- or DR5-selective apoptosis (Fig. 3C). While apoptosis triggered by the wtTRAIL was almost unaffected in HT-29 cells with suppressed expression of DR4, downregulation of DR5 attenuated wtTRAIL-induced apoptosis in these cells, thus supporting the major role of the DR5 receptor in apoptotic signaling in HT-29 cells.

\section{Both DR4 and DR5 receptor-specific ligands efficiently induce necroptosis in HT-29 cells}

Besides inducing apoptosis, activated death receptors can, under specific conditions of suppressed apoptosis, trigger the process of necroptosis. We examined the efficacy of TRAIL receptor-specific ligands in the induction of necroptotic signaling. In these experiments we used HT-29 cells, and induced pro-necroptotic conditions by their pre-treatment with the pancaspase inhibitor z-VAD and the IAP inhibitor/SMAC mimetic birinapant, which increases the cytosolic pools of RIP1, the essential kinase for the induction of necroptosis from activated death receptors. Necroptosis inhibitors necrostatin-1 (blocks RIP1 kinase activity) and necrosulfonamide (inhibits assembly of MLKL) were also used to document necroptotic cell death. HT-29 cells pre-treated with the combination of birinapant and z-VAD were subsequently treated with increasing concentrations of TST-TRAIL-wt, and dead cells were quantified using propidium iodide staining and flow cytometry. We show that TST-TRAIL-wt 
can efficiently induce necroptosis of HT-29 cells even at the low concentration of $10 \mathrm{ng} / \mathrm{ml}$, and that this type of cell death can be suppressed by necrostatin (Fig. 4A) as well as the MLKL inhibitor necrosulfonamide (Fig. 4B). Necroptosis was also confirmed by RIP3 kinase-mediated phosphorylation of the MLKL protein and the absence of caspase-3processed PARP (Fig. 4D). Notwithstanding this, we observed higher efficacy of DR5specific ligands (notably, again, DR5.2) in the case of low concentration of the TST-TRAIL ligand at $10 \mathrm{ng} / \mathrm{ml}$ (Fig. 4C). We did not notice any significant differences between DR4- and DR5-specific ligands in inducing necroptotic cell death at higher, saturating concentrations of the ligands (100 ng/ml) (Fig. 4B).

\section{DR5 receptor-specific TRAIL ligands efficiently induce NF- $\mathrm{B}$, p38 and JNK signaling under both apoptotic and necroptotic conditions}

In addition to cell death signaling, ligands from the TNF family activate various types of nonapoptotic signaling from their activated receptors, including activation of the NF- $\kappa \mathrm{B}$ pathway, MAP and stress kinases and PI3 kinases; further, and under blockage of cells death, even promotion of proliferation, migration and cells survival may occur [26]. The majority of these TRAIL-triggered signaling pathways are activated through secondary cytoplasmic complexes. Under the pro-apoptotic conditions in both HT-29 and PANC-1 or pro-necroptotic conditions in HT-29 cells, we examined the effect of receptor-specific TRAIL variants on the activation of NF- $\kappa \mathrm{B}, \mathrm{MAP}$ and stress kinases. In general, under pro-apoptotic conditions, the DR4specific TRAIL variant was less effective in triggering these signaling pathways (Fig. 5A and S4). Notably, activation/phosphorylation of JNK kinases and IאB phosphorylation was very inefficient in TST-DR4.2-treated HT-29 cells and significantly less efficient also in PANC-1 cells. Under necroptotic conditions, these differences among receptor-specific TRAIL variants were blunted in TRAIL-treated HT-29 cells (Fig. 5B), possibly reflecting similar efficacy of wild-type and receptor-specific variants in triggering necroptosis of HT-29 cells.

\section{Discussion}

The initial discovery and selective cancer cell killing properties of TRAIL have invoked great expectations for this ligand as a new biological anti-cancer agent [3, 27]. However, clinical trials in the past two decades, using either recombinant TRAIL or the receptor-specific agonistic antibodies were largely disappointing, with no or minimal effect of these agents on suppression or elimination of various tumors. Though unsuccessful, the outcome from these 
trials led to the formulation of better and possibly patient-tailored therapeutic protocols, which include the use of novel sensitizers and the discovery and preparation of modified TRAILbased agents, thus opening a new window of opportunity for its use in cancer therapy $[9,28]$. Various TRAIL receptor-specific mutants of this ligand belong among these novel formulations of TRAIL . A selective and computer design-based point mutations of TRAIL led to the preparation of highly active and DR4- or DR5-specific variants of the ligand. Based on this knowledge $[19,21,23]$, we prepared modified and highly effective and selective DR4and DR5-specific ligand variants containing, in addition to the mutated extracellular part of TRAIL, a stabilizing trimerization motif and TwinStrep tag at their $\mathrm{N}$ termini for efficient purification and DISC precipitation.

The modified DR4- and DR5-targeted TRAIL variants were, as expected from already published data, highly selective, inducing apoptosis more efficiently than TST-TRAILwt via DR5-signaling in Jurkat T cells, or DR4-signaling in Ramos B cells. As model cell lines for detailed analysis of DR4- vs. DR5-specific signaling, the colorectal HT-29 and pancreatic PANC-1 cells were selected. These two cell lines are resistant to wtTRAIL-induced apoptosis under normal conditions, but can be sensitized to undergo programmed cell death by a number of enhancing agents such as the inhibitor of translation homoharringtonine or the Bcl2/Bcl- $\mathrm{X}_{\mathrm{L}}$ inhibitor ABT-737. The initial comparative analysis of TRAIL receptor-specific ligands in colorectal HT-29 cells proved that DR5-specific ligands are more effective than DR4-targeted ligands and even wtTRAIL in the activation of caspases and the ensuing induction of apoptosis of HT-29 cells. Our data thus support other published reports pointing to the preferential use of DR5-mediated signaling in colorectal cancer cells [29, 30], but appear to contradict the recently published data from colorectal cells with gene-edited DR4 and DR5 receptors [31].

Cells with inactivated expression of DR4 become resistant to TRAIL or the DR5 peptidomimetic, pointing to DR4 as a main pro-apoptotic receptor. It might be difficult to sort out this apparent controversy, also in light of another current report that, to the contrary, documents that the DR5 receptor is the one that responds to stress triggered by unfolded protein response [32]. However, using our highly specific and effective ligands, we have confirmed their selectivity; we are therefore not convinced that DR4 is the main (or only) proapoptotic receptor, at least in the studied cell lines. It is possible that DR4 is in some cells required to support DR5-mediated signaling and thus its deletion could severely compromise DR5-triggered apoptosis. Our data pointing to significantly more effective DR5-triggered signaling in HT-29 cells, are supported by very efficient $v s$. almost no activation of JNK 
signaling by DR5-specific ligands (TST-DR5 vs. TST DR4 ligands), and in the case of the more active DR5.2 ligands strong activation of long pro-apoptotic isoforms of JNK1 [33]. Our data are also supported by the shRNA-mediated knockdown of either DR4 or DR5 expression in HT-29 cells, which in contrast to gene editing-mediated inactivation of these receptors [31], do not entirely eliminate the expression of either of these receptors, and thus allow for their possible cross-talk. In addition, we found that engagement of the DR5 receptor led to an increase in the transcription of the DR5 gene (data not shown), which could lead to increased level of the DR5 receptor and thus to more efficient DR-triggered apoptosis. Moreover, several reports document that ubiquitin-mediated degradation preferentially targets the DR4 receptor, which also likely contributes to the enhanced DR5-mediated apoptotic signaling [3436].

We also used in our study the PANC-1 pancreatic cancer cells that were reported to employ mainly DR4 in apoptosis induction [16, 18, 20, 21]. Similarly, acute myeloid leukemia cells apparently prefer DR4 receptors for triggering TRAIL-induced apoptosis [17, 37]. However, our results from the analysis of TRAIL receptor-specific apoptotic signaling in PANC-1 cells differ from majority of the above-mentioned published data. Both DR5-specific ligands and, notably, more efficient DR5.2 ligand were, despite lower cell surface expression of DR5, significantly more efficient in triggering apoptosis in PANC-1 cells by means of not only TST-TRAIL-wt but also DR4-specific ligand DR4.2. The DR5.2 ligand triggered considerable apoptosis in PANC-1 cells even in the absence of a sensitizer/enhancer. Although the initial steps in TRAIL-induced apoptosis involving assembly of DISC and DISC-mediated activation of caspase- 8 proceed similarly for the TST-TRAIL-wt and all TRAIL receptors-specific variants in HT-29 cells, DR5-specific ligands are then superior in the amplification of apoptotic signaling. There may be several reasons for these apparent controversies: a) the modified DR5-specific ligands stabilized by the TRI motif promote more effective interactions with DR5 receptors allowing them to transmit efficient apoptotic signaling; b) our ligands do not contain only the generally used 114-281 amino acids region from the extracellular part of TRAIL, but also 20 more membrane-proximal amino acids (i.e. 95-281), which could have an effect on their relative efficacy in inducing apoptotic signaling; and c) the efficacy of DR4- or DR5-triggered apoptotic signaling is apparently positively affected by O-glycosylation of DR5 [38] or N-glycosylation of DR4 [39], and thus our ligands might interact differently than other similar recombinant TRAIL receptor-specific ligands with differently glycosylated cognate receptors. Additional, possibly attractive hypothesis of the reasons for more effective DR5-triggered apoptotic signaling might encompass more 
efficient chain formation of caspase-8 in DR5-selective DISC complexes with rapid kinetics of caspase- 8 processing $[40,41]$. Our data are also in agreement with recent screenings of pancreatic and colorectal cancer cells for their response of TRAIL receptor-specific variants, pointing to the DR5 preference for PANC-1 cells, although various preferences for DR5- vs. DR4-mediated signaling were reported for different pancreatic cancer cells [30]. Indeed, we found almost equal preference for DR4- and DR5-selective apoptosis with a slight incline into DR5-triggered apoptotic signaling in other pancreatic cancer cell line PaTu (data not shown).

TRAIL death receptors can similarly as other receptors from the TNFR family trigger RIP1/RIP3-dependent necroptosis [42, 43]. Under the conditions favoring necroptosis (i.e. inhibiting caspases and the IAP proteins), wtTRAIL, as previously shown [43], induced dosedependent, necrostatin-1 suppressible necroptosis of HT-29 cells, consistent with previous findings [43]. However, in contrast to apoptosis, all DR4- and DR5-specific ligands were, at saturating concentrations, equally effective in triggering RIP1- and MLKL-dependent necroptosis in HT-29 cells. TRAIL receptor-specific ligands similarly enhanced activation of non-apoptotic signaling, such as triggering phosphorylation of p38 and JNK kinase. Notably, in spite of equal activation of necroptosis at saturating concentration of TST-TRAIL ligands, we observed higher efficacy of the DR5.2 ligand at its lower concentration, likely reflecting its higher binding affinity for the DR5 receptor [23]. One of the reasons could be related to the endocytosis and endosomal acidification [44] in a process of pro-death signaling from TRAIL receptors. In apoptotic signaling, dynamin 1-mediated endocytosis likely attenuates TRAIL-mediated apoptosis [45], but it apparently does not affect TRAIL-triggered necroptosis [46].

In conclusion, using a number of approaches, we have shown that TRAIL receptorspecific pro-apoptotic signaling in colorectal and in pancreatic cancer cells could, in contrast to the recent notion, largely rely on the DR5 death receptor, and that this dependence is blunted in TRAIL-triggered necroptosis.

\section{Acknowledgements}

We express our thanks to Jan Brazina and Jarmila Stremenova for their advice and expertise. This project was supported by institutional grants from Czech Academy of Sciences RVO: 86652036 and 68378050, Ministry of Education project Kontakt LH12202, by the Czech Science foundation grants $15-03379 \mathrm{~S}$ and 15-14789S, and by the BIOCEV European Regional Development Fund CZ.1.05/1.1.00/02.0109 


\section{Figure legends:}

Figure 1. DR5 receptor-specific TRAIL ligands effectively induce apoptosis in colorectal and pancreatic cancer cells.

Colorectal HT-29 (A-D) and pancreatic PANC-1 cells (E) were treated with TST-TRAIL variants. Cells were pre-treated with $100 \mathrm{nM} \mathrm{HHT}$ for $1 \mathrm{~h}$ and then treated with $100 \mathrm{ng} / \mathrm{ml}$ of TST-TRAIL-wt, or 4.2, 5.1 and 5.2 ligands for indicated time periods. The samples were then analyzed by western blotting (A, B). SE in Fig.1 A,B stands for the stronger exposition. For the quantification of apoptosis, HT-29 cells were pre-treated with $100 \mathrm{nM}$ HHT for $1 \mathrm{~h}(\mathrm{C})$ or with $20 \mu \mathrm{M}$ ABT-737 for $4 \mathrm{~h}$ (D), and then treated with increasing concentration (C) or with $100 \mathrm{ng} / \mathrm{ml}$ (D) of TST-TRAIL-wt, 4.2, 5.1 and 5.2 for $5 \mathrm{~h}$. PANC-1 cells (E) were pre-treated with $100 \mathrm{nM}$ HHT for $1 \mathrm{~h}$ or with $20 \mu \mathrm{M}$ ABT-737 for $4 \mathrm{~h}$ and then treated with TRAIL variants at a concentration of $100 \mathrm{ng} / \mathrm{ml}$ for $5 \mathrm{~h}$. Cells were evaluated for apoptosis using annexin V-FITC and analyzed by flow cytometry (C-E). Cell surface expression of DR4 and DR5 receptor in HT-29 and PANC-1 cell lines was evaluated by flow cytometry (F). The relative signal is calculated with respect to the control cells stained only with the secondary antibody. The total protein expression of the DR4 and DR5 receptor in the HT-29 and PANC1 cells was detected by western blotting $(\mathrm{G})$. Data in Fig. 1 C-E were analyzed by ANOVA using GraphPad Prism 6 software and are presented as mean values \pm SEM with differences at $\mathrm{p} \leq 0.05$ considered as significant. The experiments are representative of at least three biological replicates.

Figure 2. TRAIL receptor-specific variants induce efficient yet comparable DISC formation in HT-29 and PANC-1 cells.

HT-29 (A) or PANC-1 (B) cells were pre-incubated with $1 \mu \mathrm{g} / \mathrm{ml}$ of TST-TRAILs: wt, 4.2, 5.1 and 5.2 for $15 \mathrm{~min}$ on ice. The cells were then either harvested (time point $0 \mathrm{~min}$ ) or transferred to $37^{\circ} \mathrm{C}$, harvested at specified time periods $(10,20$ and $40 \mathrm{~min})$ and lysed. The DISC complexes from the cleared lysates were isolated on Streptactine agarose and analyzed by western blotting. Experiments are representative of two biological replicates. 
Figure 3. DR5 but not DR4 downregulation attenuates TRAIL-wt induced apoptosis of HT-29 cells.

shRNA-mediated suppression of the cell surface expression of DR4 and DR5 receptors in HT29 cells was analyzed by flow cytometry (A). Relative fluorescence signal was normalized to the level of the signal after staining with the secondary antibody only and then against the receptor expression in cells expressing non-targeting (NT) control shRNA. Total intracellular expression of DR4 and DR5 receptor was evaluated by western blotting (B). For the quantification of apoptosis (C), HT-29 were pre-treated with $100 \mathrm{nM}$ HHT for $1 \mathrm{~h}$ and then treated with $100 \mathrm{ng} / \mathrm{ml}$ TST-TRAIL variants for $3 \mathrm{~h}$. Cells were assessed for apoptosis using annexin V-FITC and the flow cytometry. Data in Fig. 3A,C were analyzed by ANOVA using GraphPad Prism 6 software and are presented as mean values \pm SEM with differences at $p \leq$ 0.05 considered as significant. The experiments are representative of at least three biological replicates.

Figure 4. Both DR4 and DR5 receptor-specific TRAIL ligands efficiently induce necroptosis of HT-29 cells

HT-29 cells were pre-treated with combinations of $10 \mathrm{nM}$ birinapant plus $50 \mu \mathrm{M} \mathrm{z}-\mathrm{VAD}$ or in addition with $50 \mu \mathrm{M}$ necrostatin for $1 \mathrm{~h}$ and then treated with an increasing concentration of TST-TRAIL-wt for $8 \mathrm{~h}$ (A). Necroptotic death of HT-29 cells was verified using RIP1 or MLKL inhibitors necrostatine-1 and necrosulfonamide (B). HT-29 were pre-treated with the combinations of $10 \mathrm{nM}$ birinapant, $50 \mu \mathrm{M}$ z-VAD, $50 \mu \mathrm{M}$ necrostatin and $20 \mu \mathrm{M}$ necrosulfonamide as shown for $1 \mathrm{~h}$, and then treated with $100 \mathrm{ng} / \mathrm{ml}$ of TST-TRAIL-wt, 4.2, 5.1 and 5.2 for $8 \mathrm{~h}$ (B). HT-29 cells were pre-incubated with $10 \mathrm{nM}$ birinapant and $50 \mu \mathrm{M} \mathrm{z}$ VAD for $1 \mathrm{~h}$ and then treated with increasing concentrations of TST-TRAIL ligands for $6 \mathrm{~h}$ (C). Cell death was in all cases assessed by propidium iodide staining and flow cytometry. HT-29 cells were pre-treated with the combination of $10 \mathrm{nM}$ birinapant, $50 \mu \mathrm{M} \mathrm{z}-\mathrm{VAD}$ and $50 \mu \mathrm{M}$ necrostatin for $1 \mathrm{~h}$, and then TST-TRAIL ligand variants were added at the concentration of $100 \mathrm{ng} / \mathrm{ml}$ for $3 \mathrm{~h}$ (D). Samples were analyzed by western blotting. Data in Fig. 4C were analyzed by ANOVA using GraphPad Prism 6 software and are presented as mean values \pm SEM with differences at $\mathrm{p} \leq 0.05$ considered as significant. The experiments are representative of at least three biological replicates. 
Figure 5. DR5 receptor-specific TRAIL ligands effectively induce NFKB, p38 and JNK signaling under both apoptotic and necroptotic conditions.

HT-29 cells were treated with $100 \mathrm{ng} / \mathrm{ml}$ of TST-TRAIL-wt, 4.2, 5.1 and 5.2 for 60-180 min (A) or were pre-treated with both $10 \mathrm{nM}$ birinapant and $50 \mu \mathrm{M} \mathrm{z}-\mathrm{VAD}$ for $1 \mathrm{~h}$ and then treated with $100 \mathrm{ng} / \mathrm{ml}$ of TST-TRAIL ligand variants for 60-180 min (B). Cell lysates were analyzed by western blotting. SE in Fig. 5B stands for the stronger exposition. Experiments are representative of at least three biological replicates for Fig. 5A and two for Fig. 5B.

\section{References}

[1] S.A. Marsters, R.A. Pitti, J.P. Sheridan, A. Ashkenazi, Control of apoptosis signaling by Apo2 ligand, Recent Prog Horm Res, 54 (1999) 225-234.

[2] P. Secchiero, M. Vaccarezza, A. Gonelli, G. Zauli, TNF-related apoptosis-inducing ligand (TRAIL): a potential candidate for combined treatment of hematological malignancies, Curr Pharm Des, 10 (2004) 3673-3681.

[3] H. Walczak, R.E. Miller, K. Ariail, B. Gliniak, T.S. Griffith, M. Kubin, W. Chin, J. Jones, A. Woodward, T. Le, C. Smith, P. Smolak, R.G. Goodwin, C.T. Rauch, J.C. Schuh, D.H. Lynch, Tumoricidal activity of tumor necrosis factor-related apoptosis-inducing ligand in vivo, Nat Med, 5 (1999) 157-163.

[4] S.R. Wiley, K. Schooley, P.J. Smolak, W.S. Din, C.P. Huang, J.K. Nicholl, G.R. Sutherland, T.D. Smith, C. Rauch, C.A. Smith, et al., Identification and characterization of a new member of the TNF family that induces apoptosis, Immunity, 3 (1995) 673-682.

[5] K. Azijli, S. Yuvaraj, M.P. Peppelenbosch, T. Wurdinger, H. Dekker, J. Joore, E. van Dijk, W.J. Quax, G.J. Peters, S. de Jong, F.A. Kruyt, Kinome profiling of non-canonical TRAIL signaling reveals RIP1-Src-STAT3-dependent invasion in resistant non-small cell lung cancer cells, J Cell Sci, 125 (2012) 4651-4661.

[6] F.J. Hoogwater, M.W. Nijkamp, N. Smakman, E.J. Steller, B.L. Emmink, B.F. Westendorp, D.A. Raats, M.R. Sprick, U. Schaefer, W.J. Van Houdt, M.T. De Bruijn, R.C. Schackmann, P.W. Derksen, J.P. Medema, H. Walczak, I.H. Borel Rinkes, O. Kranenburg, Oncogenic K-Ras turns death receptors into metastasis-promoting receptors in human and mouse colorectal cancer cells, Gastroenterology, 138 (2010) 2357-2367.

[7] S. von Karstedt, A. Conti, M. Nobis, A. Montinaro, T. Hartwig, J. Lemke, K. Legler, F. Annewanter, A.D. Campbell, L. Taraborrelli, A. Grosse-Wilde, J.F. Coy, M.A. El-Bahrawy, F. Bergmann, R. Koschny, J. Werner, T.M. Ganten, T. Schweiger, K. Hoetzenecker, I. Kenessey, B. Hegedus, M. Bergmann, C. Hauser, J.H. Egberts, T. Becker, C. Rocken, H. 
Kalthoff, A. Trauzold, K.I. Anderson, O.J. Sansom, H. Walczak, Cancer cell-autonomous TRAIL-R signaling promotes KRAS-driven cancer progression, invasion, and metastasis, Cancer Cell, 27 (2015) 561-573.

[8] S. Grootjans, T. Vanden Berghe, P. Vandenabeele, Initiation and execution mechanisms of necroptosis: an overview, Cell Death Differ, 24 (2017) 1184-1195.

[9] S. von Karstedt, A. Montinaro, H. Walczak, Exploring the TRAILs less travelled: TRAIL in cancer biology and therapy, Nat Rev Cancer, 17 (2017) 352-366.

[10] J. Lemke, S. von Karstedt, J. Zinngrebe, H. Walczak, Getting TRAIL back on track for cancer therapy, Cell Death Differ, 21 (2014) 1350-1364.

[11] B. Lim, J.E. Allen, V.V. Prabhu, M.K. Talekar, N.K. Finnberg, W.S. El-Deiry, Targeting TRAIL in the treatment of cancer: new developments, Expert Opin Ther Targets, 19 (2015) 1171-1185.

[12] J.B. Funcke, V. Zoller, M.A. El Hay, K.M. Debatin, M. Wabitsch, P. Fischer-Posovszky, TNF-related apoptosis-inducing ligand promotes human preadipocyte proliferation via ERK1/2 activation, FASEB J, 29 (2015) 3065-3075.

[13] T. Hartwig, A. Montinaro, S. von Karstedt, A. Sevko, S. Surinova, A. Chakravarthy, L. Taraborrelli, P. Draber, E. Lafont, F. Arce Vargas, M.A. El-Bahrawy, S.A. Quezada, H. Walczak, The TRAIL-Induced Cancer Secretome Promotes a Tumor-Supportive Immune Microenvironment via CCR2, Mol Cell, 65 (2017) 730-742 e735.

[14] D. Siegmund, I. Lang, H. Wajant, Cell death-independent activities of the death receptors CD95, TRAILR1, and TRAILR2, FEBS J, 284 (2017) 1131-1159.

[15] S.K. Kelley, A. Ashkenazi, Targeting death receptors in cancer with Apo2L/TRAIL, Curr Opin Pharmacol, 4 (2004) 333-339.

[16] J. Lemke, A. Noack, D. Adam, V. Tchikov, U. Bertsch, C. Roder, S. Schutze, H. Wajant, H. Kalthoff, A. Trauzold, TRAIL signaling is mediated by DR4 in pancreatic tumor cells despite the expression of functional DR5, J Mol Med (Berl), 88 (2010) 729-740.

[17] M. MacFarlane, S.L. Kohlhaas, M.J. Sutcliffe, M.J. Dyer, G.M. Cohen, TRAIL receptorselective mutants signal to apoptosis via TRAIL-R1 in primary lymphoid malignancies, Cancer Res, 65 (2005) 11265-11270.

[18] D. Stadel, A. Mohr, C. Ref, M. MacFarlane, S. Zhou, R. Humphreys, M. Bachem, G. Cohen, P. Moller, R.M. Zwacka, K.M. Debatin, S. Fulda, TRAIL-induced apoptosis is preferentially mediated via TRAIL receptor 1 in pancreatic carcinoma cells and profoundly enhanced by XIAP inhibitors, Clin Cancer Res, 16 (2010) 5734-5749. 
[19] A.M. van der Sloot, V. Tur, E. Szegezdi, M.M. Mullally, R.H. Cool, A. Samali, L. Serrano, W.J. Quax, Designed tumor necrosis factor-related apoptosis-inducing ligand variants initiating apoptosis exclusively via the DR5 receptor, Proc Natl Acad Sci U S A, 103 (2006) 8634-8639.

[20] R. Yu, S.M. Albarenque, R.H. Cool, W.J. Quax, A. Mohr, R.M. Zwacka, DR4 specific TRAIL variants are more efficacious than wild-type TRAIL in pancreatic cancer, Cancer Biol Ther, 15 (2014) 1658-1666.

[21] C.R. Reis, A.M. van der Sloot, A. Natoni, E. Szegezdi, R. Setroikromo, M. Meijer, K. Sjollema, F. Stricher, R.H. Cool, A. Samali, L. Serrano, W.J. Quax, Rapid and efficient cancer cell killing mediated by high-affinity death receptor homotrimerizing TRAIL variants, Cell Death Dis, 1 (2010) e83.

[22] K. Papanikolopoulou, G. Schoehn, V. Forge, V.T. Forsyth, C. Riekel, J.F. Hernandez, R.W. Ruigrok, A. Mitraki, Amyloid fibril formation from sequences of a natural betastructured fibrous protein, the adenovirus fiber, J Biol Chem, 280 (2005) 2481-2490.

[23] M.E. Gasparian, B.V. Chernyak, D.A. Dolgikh, A.V. Yagolovich, E.N. Popova, A.M. Sycheva, S.A. Moshkovskii, M.P. Kirpichnikov, Generation of new TRAIL mutants DR5-A and DR5-B with improved selectivity to death receptor 5, Apoptosis, 14 (2009) 778-787.

[24] L. Beranova, A.R. Pombinho, J. Spegarova, M. Koc, M. Klanova, J. Molinsky, P. Klener, P. Bartunek, L. Andera, The plant alkaloid and anti-leukemia drug homoharringtonine sensitizes resistant human colorectal carcinoma cells to TRAIL-induced apoptosis via multiple mechanisms, Apoptosis, 18 (2013) 739-750.

[25] M. Klanova, L. Andera, J. Brazina, J. Svadlenka, S. Benesova, J. Soukup, D. Prukova, D. Vejmelkova, R. Jaksa, K. Helman, P. Vockova, L. Lateckova, J. Molinsky, B.C. Maswabi, M. Alam, R. Kodet, R. Pytlik, M. Trneny, P. Klener, Targeting of BCL2 Family Proteins with ABT-199 and Homoharringtonine Reveals BCL2- and MCL1-Dependent Subgroups of Diffuse Large B-Cell Lymphoma, Clin Cancer Res, 22 (2016) 1138-1149.

[26] K. Azijli, B. Weyhenmeyer, G.J. Peters, S. de Jong, F.A. Kruyt, Non-canonical kinase signaling by the death ligand TRAIL in cancer cells: discord in the death receptor family, Cell Death Differ, 20 (2013) 858-868.

[27] A. Ashkenazi, R.C. Pai, S. Fong, S. Leung, D.A. Lawrence, S.A. Marsters, C. Blackie, L. Chang, A.E. McMurtrey, A. Hebert, L. DeForge, I.L. Koumenis, D. Lewis, L. Harris, J. Bussiere, H. Koeppen, Z. Shahrokh, R.H. Schwall, Safety and antitumor activity of recombinant soluble Apo2 ligand, J Clin Invest, 104 (1999) 155-162. 
[28] D. de Miguel, J. Lemke, A. Anel, H. Walczak, L. Martinez-Lostao, Onto better TRAILs for cancer treatment, Cell Death Differ, 23 (2016) 733-747.

[29] R.F. Kelley, K. Totpal, S.H. Lindstrom, M. Mathieu, K. Billeci, L. Deforge, R. Pai, S.G. Hymowitz, A. Ashkenazi, Receptor-selective mutants of apoptosis-inducing ligand 2/tumor necrosis factor-related apoptosis-inducing ligand reveal a greater contribution of death receptor (DR) 5 than DR4 to apoptosis signaling, J Biol Chem, 280 (2005) 2205-2212.

[30] A. Mohr, R. Yu, R.M. Zwacka, TRAIL-receptor preferences in pancreatic cancer cells revisited: Both TRAIL-R1 and TRAIL-R2 have a licence to kill, BMC Cancer, 15 (2015) 494. [31] F. Dufour, T. Rattier, A.A. Constantinescu, L. Zischler, A. Morle, H. Ben Mabrouk, E. Humblin, G. Jacquemin, E. Szegezdi, F. Delacote, N. Marrakchi, G. Guichard, C. PellatDeceunynck, P. Vacher, P. Legembre, C. Garrido, O. Micheau, TRAIL receptor gene editing unveils TRAIL-R1 as a master player of apoptosis induced by TRAIL and ER stress, Oncotarget, 8 (2017) 9974-9985.

[32] M. Lu, D.A. Lawrence, S. Marsters, D. Acosta-Alvear, P. Kimmig, A.S. Mendez, A.W. Paton, J.C. Paton, P. Walter, A. Ashkenazi, Opposing unfolded-protein-response signals converge on death receptor 5 to control apoptosis, Science, 345 (2014) 98-101.

[33] D. Mahalingam, M. Keane, G. Pirianov, H. Mehmet, A. Samali, E. Szegezdi, Differential activation of JNK1 isoforms by TRAIL receptors modulate apoptosis of colon cancer cell lines, Br J Cancer, 100 (2009) 1415-1424.

[34] X. Liu, P. Yue, S. Chen, L. Hu, S. Lonial, F.R. Khuri, S.Y. Sun, The proteasome inhibitor PS-341 (bortezomib) up-regulates DR5 expression leading to induction of apoptosis and enhancement of TRAIL-induced apoptosis despite up-regulation of c-FLIP and survivin expression in human NSCLC cells, Cancer Res, 67 (2007) 4981-4988.

[35] J.J. Song, M.J. Szczepanski, S.Y. Kim, J.H. Kim, J.Y. An, Y.T. Kwon, M.A. Alcala, Jr., D.L. Bartlett, Y.J. Lee, c-Cbl-mediated degradation of TRAIL receptors is responsible for the development of the early phase of TRAIL resistance, Cell Signal, 22 (2010) 553-563.

[36] B. van de Kooij, I. Verbrugge, E. de Vries, M. Gijsen, V. Montserrat, C. Maas, J. Neefjes, J. Borst, Ubiquitination by the membrane-associated RING-CH-8 (MARCH-8) ligase controls steady-state cell surface expression of tumor necrosis factor-related apoptosis inducing ligand (TRAIL) receptor 1, J Biol Chem, 288 (2013) 6617-6628.

[37] E. Szegezdi, C.R. Reis, A.M. van der Sloot, A. Natoni, A. O'Reilly, J. Reeve, R.H. Cool, M. O'Dwyer, S. Knapper, L. Serrano, W.J. Quax, A. Samali, Targeting AML through DR4 with a novel variant of rhTRAIL, J Cell Mol Med, 15 (2011) 2216-2231. 
[38] K.W. Wagner, E.A. Punnoose, T. Januario, D.A. Lawrence, R.M. Pitti, K. Lancaster, D. Lee, M. von Goetz, S.F. Yee, K. Totpal, L. Huw, V. Katta, G. Cavet, S.G. Hymowitz, L. Amler, A. Ashkenazi, Death-receptor O-glycosylation controls tumor-cell sensitivity to the proapoptotic ligand Apo2L/TRAIL, Nat Med, 13 (2007) 1070-1077.

[39] F. Dufour, T. Rattier, S. Shirley, G. Picarda, A.A. Constantinescu, A. Morle, A.B. Zakaria, G. Marcion, S. Causse, E. Szegezdi, D.M. Zajonc, R. Seigneuric, G. Guichard, T. Gharbi, F. Picaud, G. Herlem, C. Garrido, P. Schneider, C.A. Benedict, O. Micheau, Nglycosylation of mouse TRAIL-R and human TRAIL-R1 enhances TRAIL-induced death, Cell Death Differ, 24 (2017) 500-510.

[40] L.S. Dickens, R.S. Boyd, R. Jukes-Jones, M.A. Hughes, G.L. Robinson, L. Fairall, J.W. Schwabe, K. Cain, M. Macfarlane, A death effector domain chain DISC model reveals a crucial role for caspase- 8 chain assembly in mediating apoptotic cell death, Mol Cell, 47 (2012) 291-305.

[41] K. Schleich, U. Warnken, N. Fricker, S. Ozturk, P. Richter, K. Kammerer, M. Schnolzer, P.H. Krammer, I.N. Lavrik, Stoichiometry of the CD95 death-inducing signaling complex: experimental and modeling evidence for a death effector domain chain model, Mol Cell, 47 (2012) 306-319.

[42] S. Jouan-Lanhouet, M.I. Arshad, C. Piquet-Pellorce, C. Martin-Chouly, G. Le MoigneMuller, F. Van Herreweghe, N. Takahashi, O. Sergent, D. Lagadic-Gossmann, P. Vandenabeele, M. Samson, M.T. Dimanche-Boitrel, TRAIL induces necroptosis involving RIPK1/RIPK3-dependent PARP-1 activation, Cell Death Differ, 19 (2012) 2003-2014.

[43] S. Voigt, S. Philipp, P. Davarnia, S. Winoto-Morbach, C. Roder, C. Arenz, A. Trauzold, D. Kabelitz, S. Schutze, H. Kalthoff, D. Adam, TRAIL-induced programmed necrosis as a novel approach to eliminate tumor cells, BMC Cancer, 14 (2014) 74.

[44] V. Horova, N. Hradilova, I. Jelinkova, M. Koc, J. Svadlenka, J. Brazina, M. Klima, J. Slavik, A. Hyrslova Vaculova, L. Andera, Inhibition of vacuolar ATPase attenuates the TRAIL-induced activation of caspase- 8 and modulates the trafficking of TRAIL receptosomes, FEBS J, 280 (2013) 3436-3450.

[45] C.R. Reis, P.H. Chen, N. Bendris, S.L. Schmid, TRAIL-death receptor endocytosis and apoptosis are selectively regulated by dynamin-1 activation, Proc Natl Acad Sci U S A, 114 (2017) 504-509.

[46] J. Sosna, S. Philipp, J. Fuchslocher Chico, C. Saggau, J. Fritsch, A. Foll, J. Plenge, C. Arenz, T. Pinkert, H. Kalthoff, A. Trauzold, I. Schmitz, S. Schutze, D. Adam, Differences and 
Similarities in TRAIL- and Tumor Necrosis Factor-Mediated Necroptotic Signaling in Cancer Cells, Mol Cell Biol, 36 (2016) 2626-2644. 


\section{Highlights}

- Use of modified TRAIL receptors DR4- or DR5-selective ligands revealed stronger preference for DR5-triggerd apoptotic signaling in selected colorectal and pancreatic cancer cells.

- DR5-triggered enhanced activation of stress kinases can contribute to pro-apoptotic signaling.

- In contrast to the induction of apoptosis, the necroptotic signaling is similarly activated by DR4- or DR5-specific ligands. 

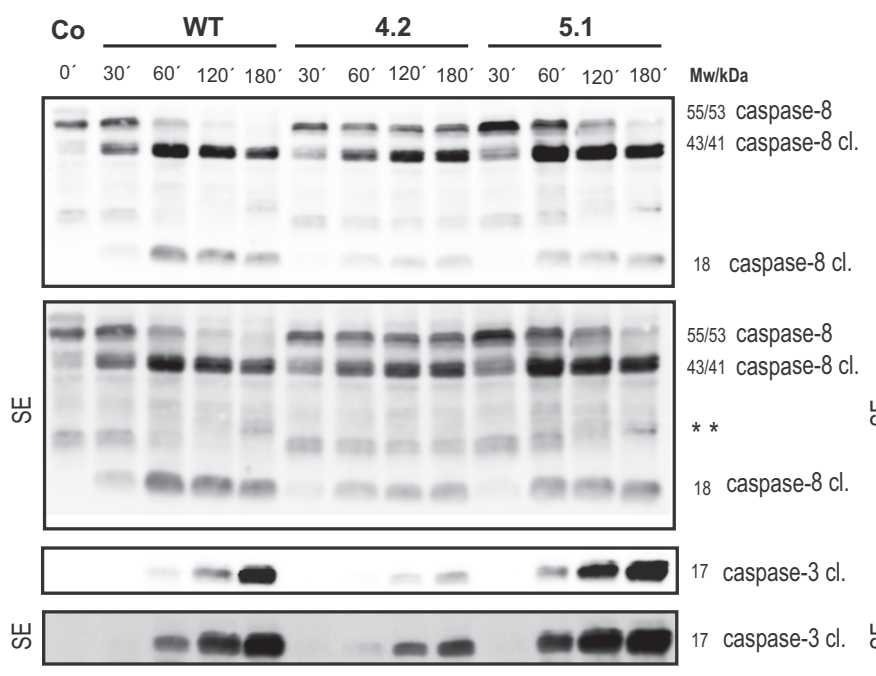

17 caspase- $3 \mathrm{cl}$.

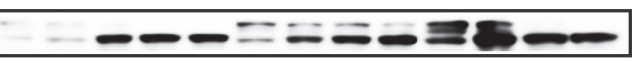

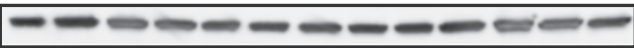

* * unspecific band

55/53 caspase- 8 43/41 caspase- $8 \mathrm{cl}$.

17 caspase-3 cl.

85 PARP cl.

$42 \beta$-actin
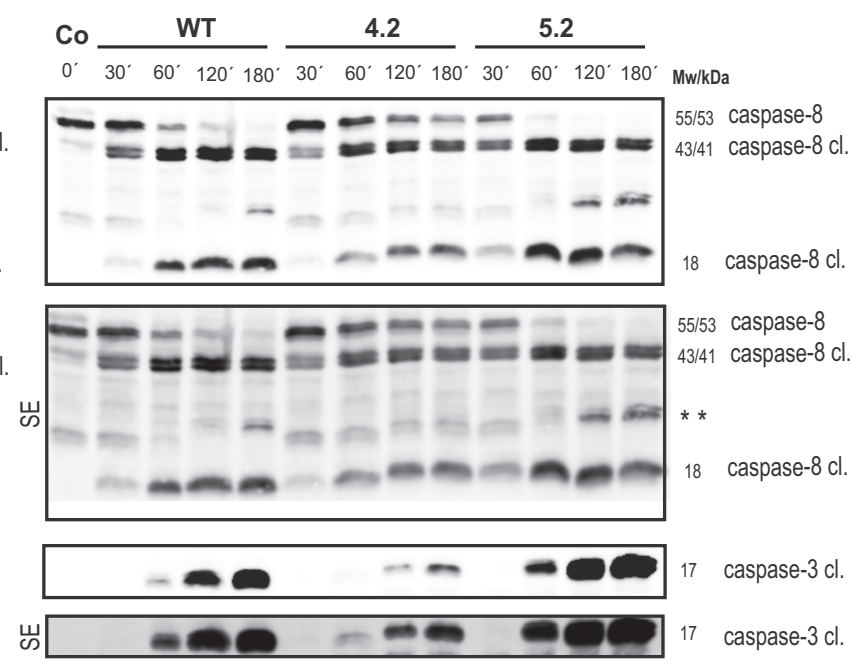

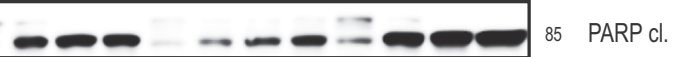

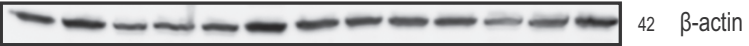

* * unspecific band

C

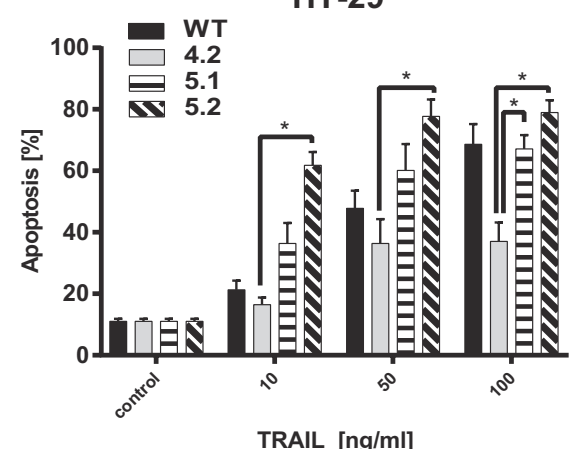

F
D

HT-29

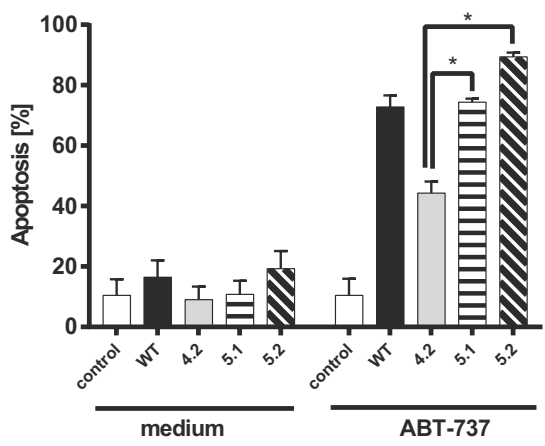

PANC-1

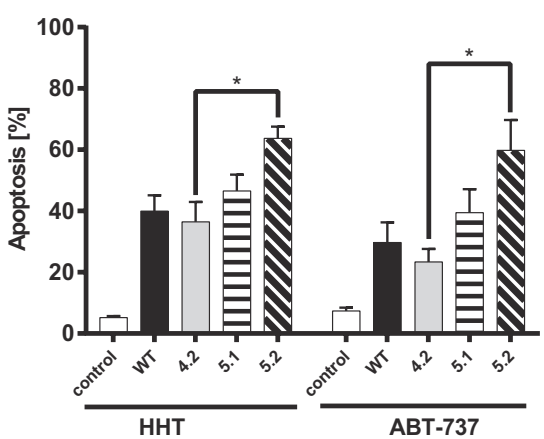

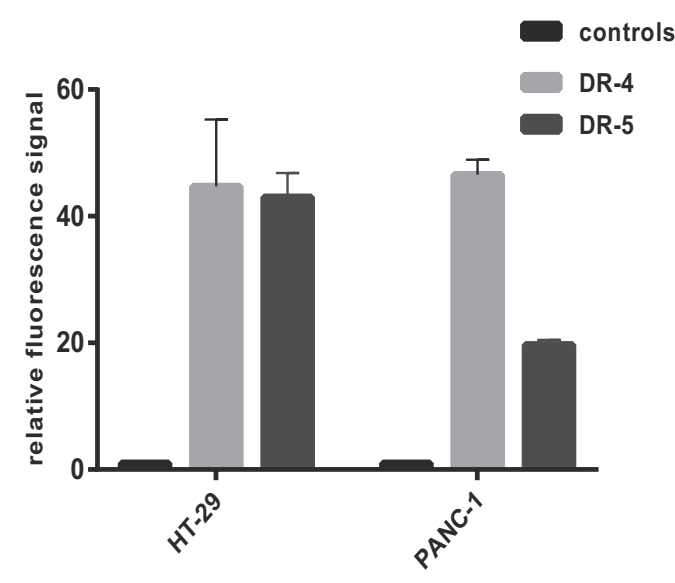

G

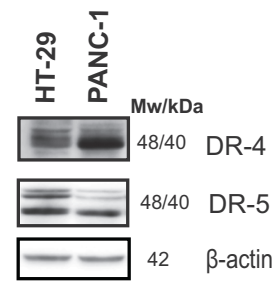




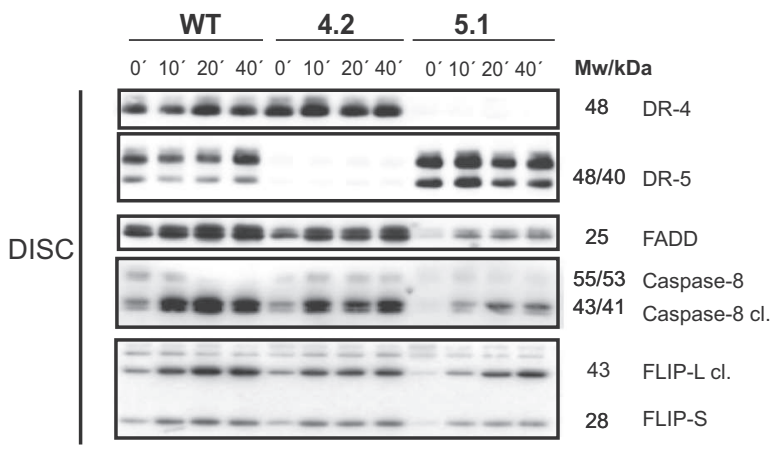

WT $\frac{4.2}{5.1}$ $0^{\prime} 10^{\circ} 20^{\circ} 40^{\circ} 0^{\prime} 10^{\prime} 20^{\prime} 40^{\circ} 0^{\prime} 10^{\prime} 20^{\circ} 40^{\circ} \mathrm{Mw} / \mathrm{kDa}$

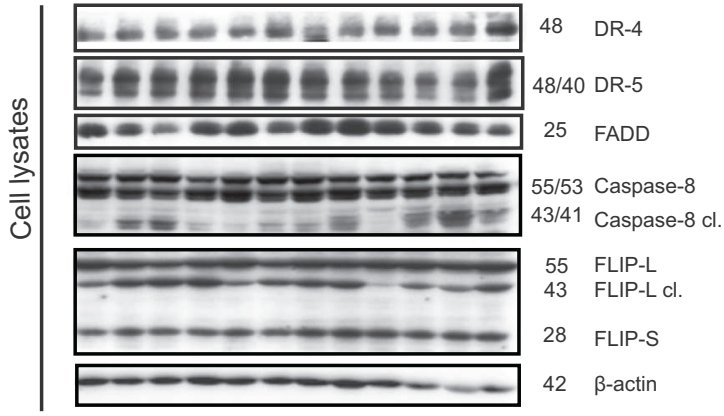

B

PANC-1
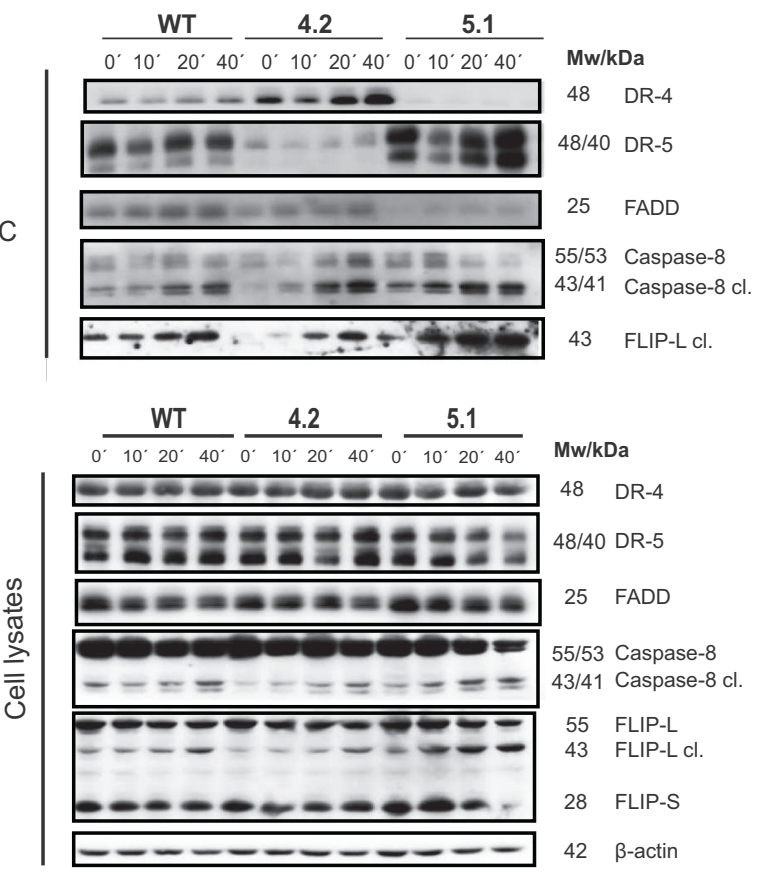

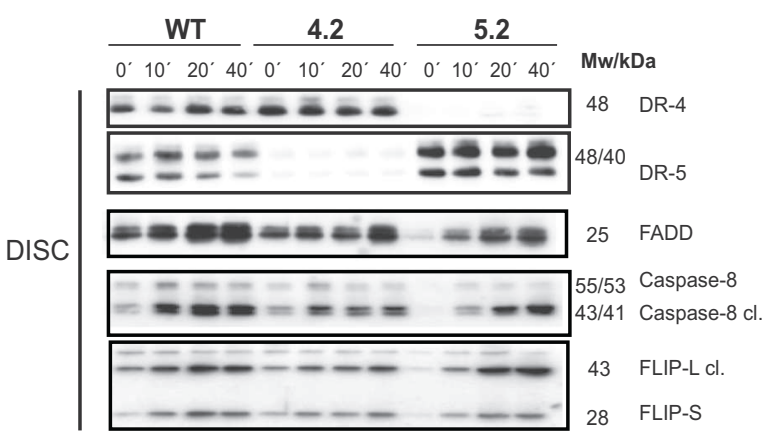

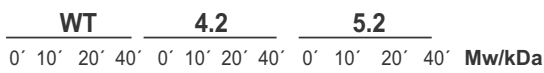

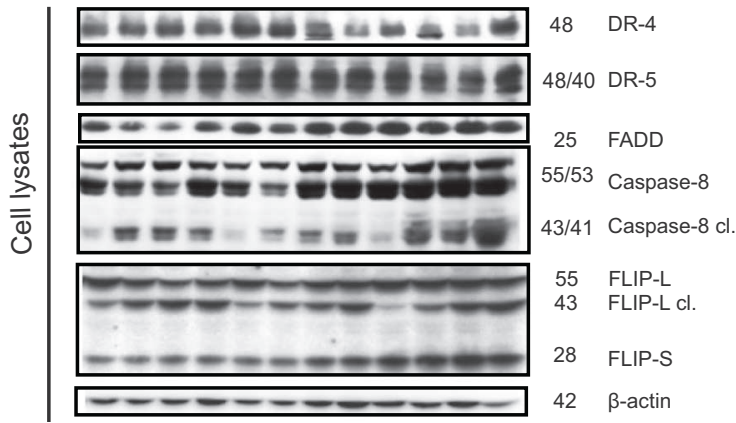

DISC

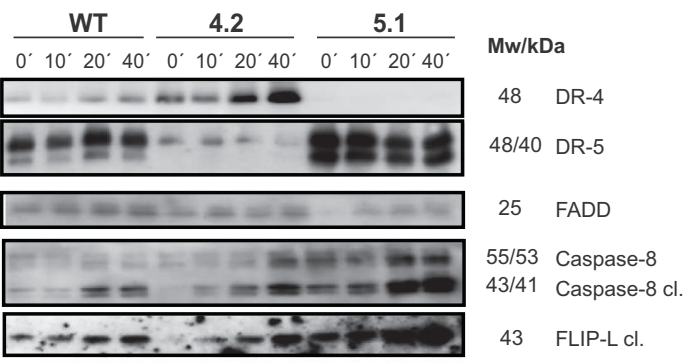

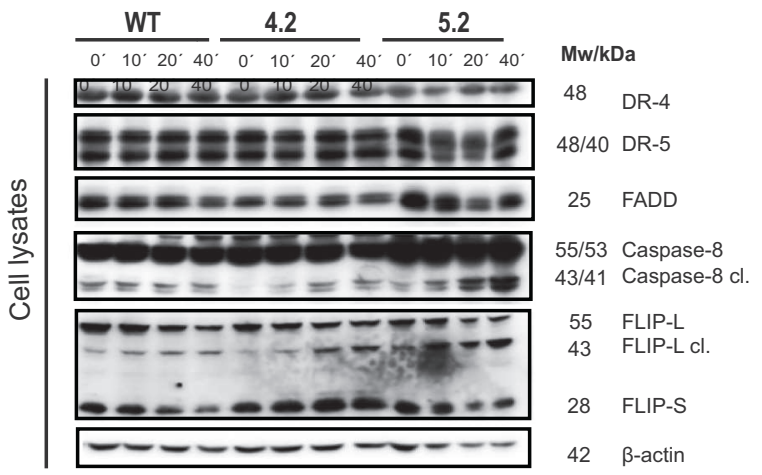


A

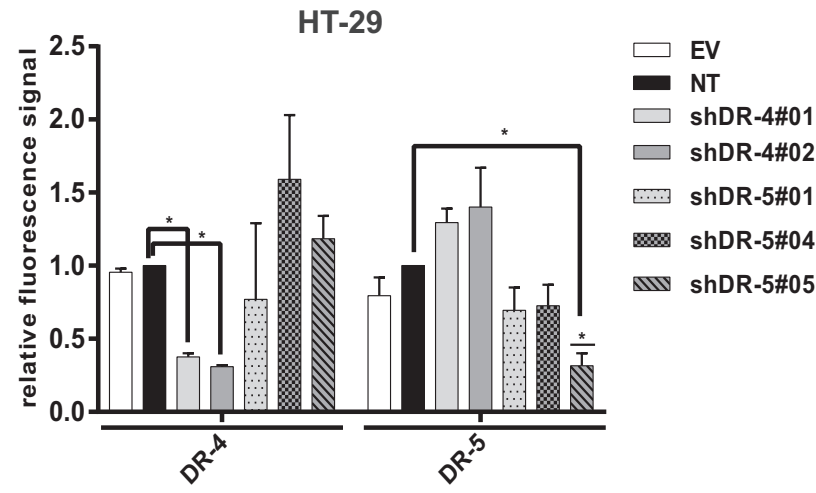

B

HT-29

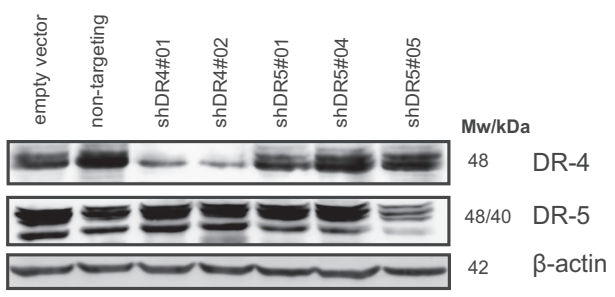

C

- TST-TRAIL WT

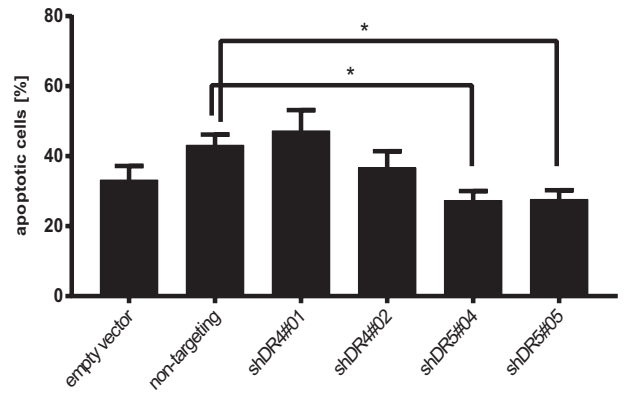

TST-TRAIL 4-2

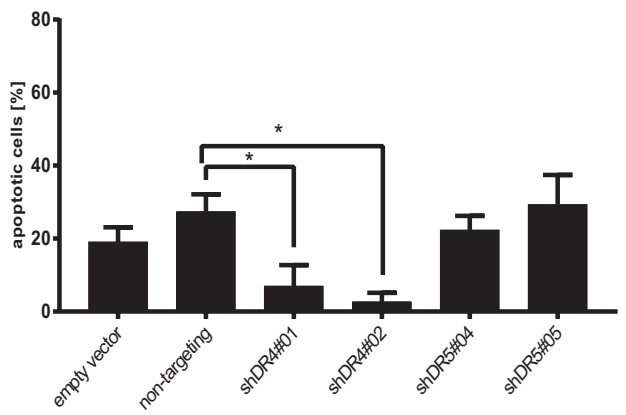

— TST-TRAIL 5-1

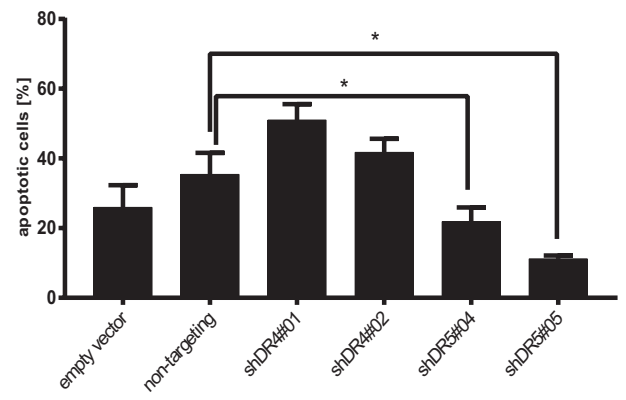

TST-TRAIL 5-2

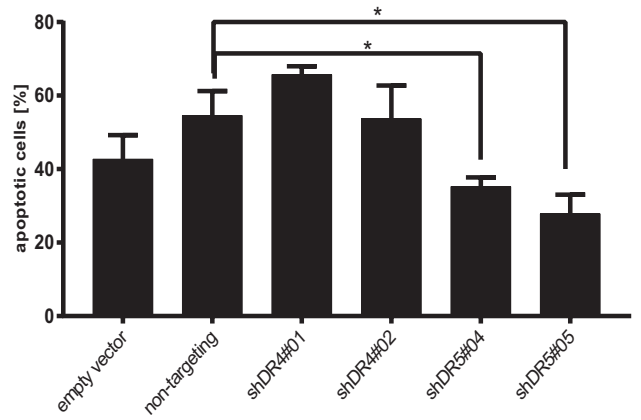

Figure 3 
A

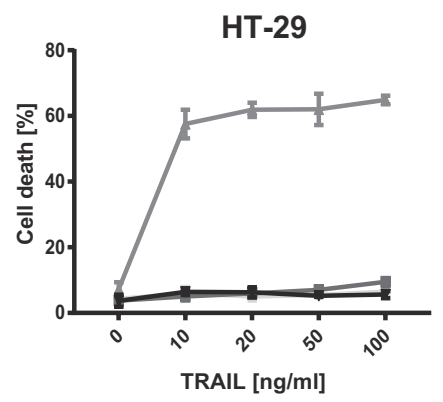

C

\section{HT-29}

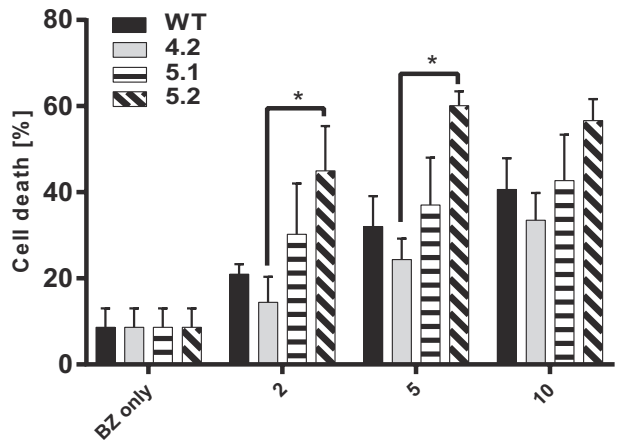

TRAIL [ng/ml]
B

HT-29
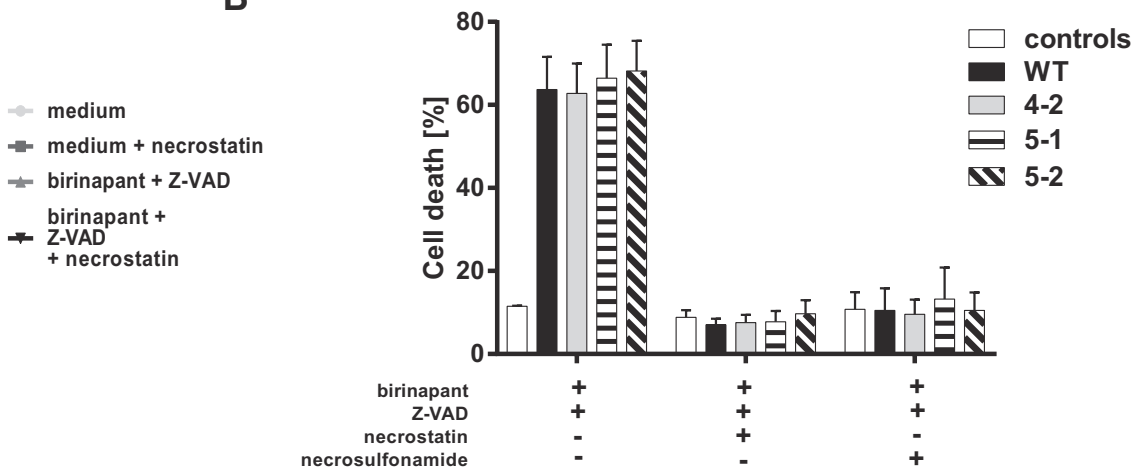

D

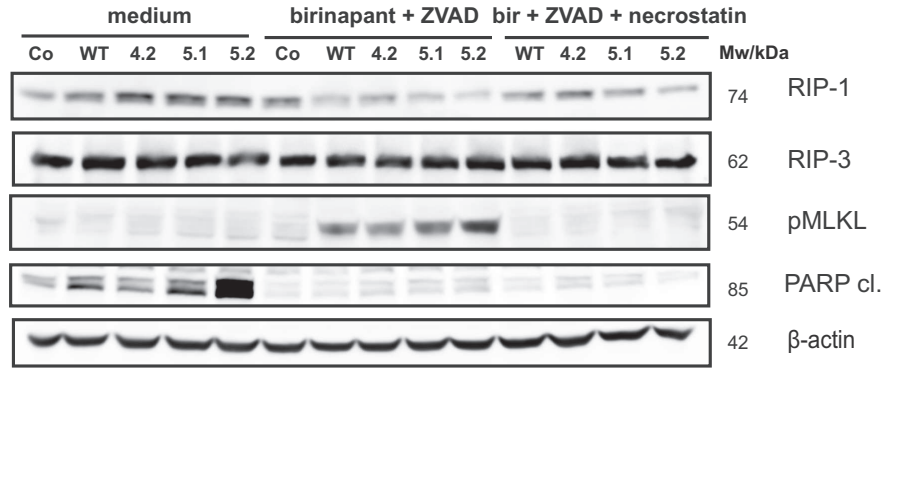

Figure 4 
A

\section{HT-29}

WT

4.2

5.1

WT

4.2

5.2

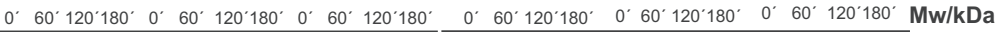

- -

- - -

b-

$-0-\infty-\infty,-\infty \quad-\infty$ p-lkba

\begin{tabular}{|l|l|l|}
\hline$-\infty$ & p38 \\
\hline$-\infty 6-\infty-\infty-\infty$ & p-p38
\end{tabular}

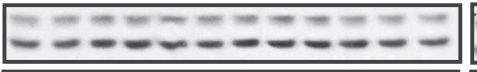

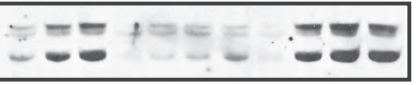

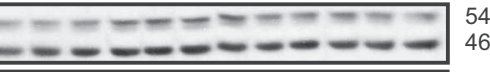

SAPK/JNK

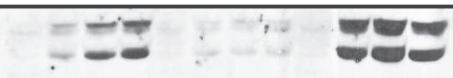

$54 \quad \mathrm{p}-\mathrm{SAPK} / \mathrm{JNK}$

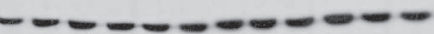

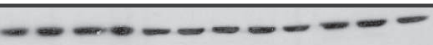

$42 \beta$-actin

B

\section{HT-29}

$\frac{\text { WT }}{0^{\prime} \quad 60^{\circ} 120^{\circ} 180^{\circ}} \frac{\mathbf{4 . 2}}{60^{\circ} 120^{\circ} 180^{\circ}} \frac{\mathbf{5 . 1}}{60^{\circ} 120^{\prime} 180^{\circ}} \frac{\mathbf{5 . 2}}{60^{\circ} 120^{\circ} 180^{\circ}}$ Mw/kDa

$--\cdots-\cdots-\cdots$

$--------\infty$

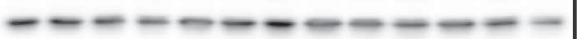

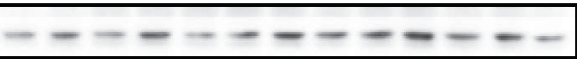

山

$-\infty-0-00000-0$

$-----1-\infty-1$

$-m-\infty-\infty-\infty-\infty$

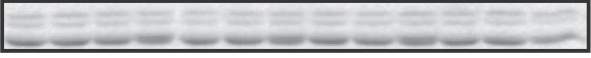

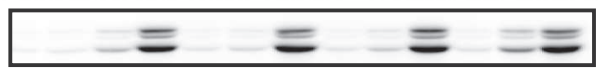

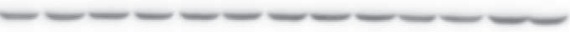

$65 \quad p 65$

65 p-p65

$40 \quad$ Ikba

$40 \mathrm{p}-\mathrm{lkba}$

40 p-lkba

$38 \quad$ p38

$38 \quad p-p 38$

SAPK/JNK

p-SAPK/JNK

$42 \beta$-actin 